\title{
Profiling of microRNAs in AML cells following overexpression or silencing of the VEGF gene
}

\author{
LI LI, LIXIA ZHU, YUNGUI WANG, DE ZHOU, JINGJING ZHU, WANZHUO XIE and XIUJIN YE \\ Department of Hematology, The First Affiliated Hospital of Zhejiang University School of Medicine, \\ Hangzhou, Zhejiang 310003, P.R. China
}

Received May 31, 2015; Accepted October 19, 2016

DOI: $10.3892 / \mathrm{ol} .2016 .5412$

\begin{abstract}
Acute myeloid leukemia (AML) is a disease of the hematopoietic progenitor cells associated with heterogeneous clonal proliferation. Vascular endothelial growth factor (VEGF) and its receptors play important roles in the regulation of angiogenesis during physiological and pathological processes. It is thought that AML cells have an autocrine VEGF pathway that contributes to the development and progression of AML. In addition, growing evidence has suggested that numerous microRNAs are involved in AML. The present study aimed to investigate the relationship between VEGF dysregulation and microRNA profiles in AML cells and patients. VEGF-overexpressing and VEGF-knockdown leukemia cells were constructed and changes in the patterns of microRNA expression were analyzed using a microRNA array. Subsequently, mononuclear cells from the blood of patients with AML showing high or low expression levels of VEGF were obtained and were used to assess the patterns of microRNA expression by reverse transcription-quantitative polymerase chain reaction. The results of the present study suggested that downregulation of VEGF markedly altered the profile of microRNAs in AML cells, while upregulation of VEGF did not. Examination of clinical samples from patients with AML showed that several microRNAs were closely associated with the expression level of VEGF, including miR-20a, miR-93, miR-16-5p, miR-17-5p, miR-124-5p and miR-17-3p. These results suggested that VEGF may be a pivotal protein that can both receive and initiate signals in leukemia cells.
\end{abstract}

Correspondence to: Professor Xiujin Ye, Department of Hematology, The First Affiliated Hospital of Zhejiang University School of Medicine, 79 Qingchun Road, Shangcheng, Hangzhou, Zhejiang 310003, P.R. China

E-mail: yxjsunny@163.com

Key words: vascular endothelial growth factor, acute myeloid leukemia, microRNA profiling

\section{Introduction}

Vascular endothelial growth factor (VEGF) and its receptors play important roles in regulating angiogenesis during physiological or pathological processes such as tumorigenesis $(1,2)$. Angiogenesis has been shown to promote the growth of solid and hematological tumors (1). VEGF, which is a glycoprotein, has five isotypes, including VEGF-A, VEGF-B, VEGF-C, VEGF-D and placental growth factor. VEGF-A is typically referred to as VEGF (3). VEGF receptors (VEGFRs) consist of three structurally similar tyrosine kinase receptor proteins termed VEGFR1 [also called Fms-related tyrosine kinase (FTL) 1], VEGFR2 (also called kinase insert domain receptor) and VEGF3 (also called FLT4) (2). VEGF is the ligand of VEGFR1 and VEGFR2, which, upon binding to VEGF, induce the proliferation of endothelial cells via the Ras- or protein kinase $\mathrm{C}$-activated mitogen-activated protein kinase signaling pathway to promote angiogenesis (2). The active form of VEGF is a homodimer that is capable of binding to VEGFRs (1).

Acute myeloid leukemia (AML), which is a disease of the hematopoietic progenitor cells characterized by heterogeneous clonal proliferation, is the most common myeloid malignancy in adults. The age of onset is late in life, and the median age is 70 years (4). Although several advances in the molecular understanding of AML have been achieved, additional studies are required in order to cure or conquer this disease $(4,5)$. Commonly, VEGF is expressed at higher levels in AML cells, and autocrine regulation of VEGF affects the clonal proliferation of AML cells (6). Compared with healthy individuals, $85 \%$ of AML patients showed upregulation of VEGF in bone marrow biopsy specimens (7). In addition, VEGFRs have been shown to be recurrently upregulated in AML (8). AML cells may possess a VEGF autocrine pathway, and its type I receptor (VEGFR1) may be involved in cellular proliferation of the M3 subtype of AML $(9,10)$.

MicroRNAs consist of a set of 19-25-nucleotide single-stranded RNA molecules that are involved in the transcription and translation of genes associated with growth, development and pathological processes such as cancer (11). Increasingly, evidence has suggested that there is a close association between AML and microRNAs (12-15). MicroRNAs may have a role in the regulation of the cellular biology and molecular genetics of AML, since upregulation of miR-155, 
miR-10a, miR-10b and miR-191 has commonly been observed in AML cells (15).

Although significant progress has been made, the functions of VEGF and microRNAs in the development and progression of AML, and the association between VEGF and microRNAs, are unclear. Therefore, the present study aimed to determine the association between VEGF overexpression and microRNA profiles in AML cells and patients.

\section{Materials and methods}

Construction of lentiviral vectors and stable cell lines. Polymerase chain reaction (PCR) was used to obtain the VEGF gene expression sequence (NM_001171626), which was inserted into a LV5 vector (Shanghai GenePharma, Co., Ltd., Shanghai, China) using the Not I/Nsi I restriction enzymes to construct the LV-VEGF expression vector, as described previously (15). LV-NC served as the control vector. The VEGF-specific short hairpin (sh)RNA sequence, TTCTCCGAACGTGTC ACGT, was obtained from Shanghai GenePharma, Co., Ltd. Following infection of the AML cell lines, K562, HL-60 and U937 (Type Culture Collection of the Chinese Academy of Sciences, Shanghai, China) with the lentiviral vectors or VEGF-specific shRNA, infected cells were selected using purimycin (Sigma-Aldrich; Merck Millipore, Darmstadt, Germany) and untransfected cells were removed $48 \mathrm{~h}$ later, as described previously (16).

RNA extraction and reverse transcription-quantitative $P C R$ $(R T-q P C R)$. Total RNA was extracted from the cells using TRIzol (Thermo Fisher Scientific, Inc., Waltham, MA, USA), as described previously (17). Total RNA was dissolved in diethylpyrocarbonate water and the optical density was measured at 260 and $280 \mathrm{~nm}$ using a NanoDrop 2000 spectrophotometer (Thermo Fisher Scientific, Inc.). The PrimeScript ${ }^{\mathrm{TM}}$ RT reagent kit with gDNA Eraser (Perfect Real Time) (Takara Biotechnology Co., Ltd., Dalian, China) was used for cDNA production from RNA, according to the manufacturer's protocol (18). The SYBR ${ }^{\circledR}$ Premix Ex Taq ${ }^{\mathrm{TM}}$ II (Tli RNaseH Plus) (Takara Biotechnology Co., Ltd.) kit was used for qPCR on a StepOnePlus $^{\mathrm{TM}}$ Real-Time PCR instrument (Thermo Fisher Scientific, Inc.). The cycling conditions were $95^{\circ} \mathrm{C}$ for $5 \mathrm{~min}$, followed by 40 cycles at $95^{\circ} \mathrm{C}$ for $10 \mathrm{sec}$ and $60^{\circ} \mathrm{C}$ for $34 \mathrm{sec}$. The primers were as follows: VEGF forward, 5'-CGCAGCTACTGCCAT CCAAT-3' and reverse, 5'-GTGAGGTTTGATCCGCATAAT CT-3'; and GAPDH forward, 3'-ACCCAGAAGACTGTGGAT GG-5'; and reverse, 3'-TCTAGACGGCAGGTCAGGTC-5'. The relative expression of the gene was calculated using the $2^{-\Delta \Delta \mathrm{Cq}}$ method (19), with GAPDH as an internal control gene.

Western blot analysis. After reaching 80-90\% confluence, the cells in culture plates were lysed using radioimmunoprecipitation assay buffer (Beyotime Institute of Biotechnology, Haimen, China) supplemented with $1 \mathrm{mM}$ phenylmethylsulfonyl fluoride protease inhibitor (Beyotime Institute of Biotechnology). The concentrations of proteins were determined using the bicinchoninic acid assay kit (Beyotime Institute of Biotechnology). The proteins were boiled following addition of the sample loading buffer and the denatured proteins were separated by $10 \%$ SDS-PAGE and transferred
Table I. Characteristics of acute myeloid leukemia patients.

Characteristic

Number of patients

\begin{tabular}{lc}
\hline Total & 45 \\
Male & 25 \\
Female & 20 \\
FAB subtype & \\
m0 & 1 \\
m2 & 20 \\
m3 & 12 \\
m5b & 12 \\
\hline
\end{tabular}

FAB subtype, French-American-British classification system.

onto polyvinylidene difluoride membranes, which were blocked with $5 \%$ bovine serum albumin (Beyotime Institute of Biotechnology), as previously described (20). Subsequently, the membranes were incubated with primary antibodies against VEGF (cat. no. ab106041; 1:1,000 dilution; Abcam, Cambridge, MA, USA) and $\beta$-actin (cat. no. ab106045; 1:5,000 dilution; Abcam), followed by incubation with the secondary antibody (cat. no. ab6721; 1:5,000 dilution; Abcam). The bands of proteins were visualized using enhanced chemiluminesence (EMD Millipore, Billerica, MA, USA) and detected with the ChemiDoc MP imager (Bio-Rad Laboratories, Inc., Hercules, CA, USA).

microRNA array. Total RNA was extracted from cells showing upregulation or downregulation of VEGF using the mirVana PARIS miRNA isolation kit (Ambion; Thermo Fisher Scientific, Inc.), according to the manufacturer's protocol. After quantitation of the RNA using the NanoDrop 2000c spectrophotometer (Thermo Fisher Scientific, Inc.), microRNA expression profiling was performed using the Exiqon A/S Technology Platform (Exiqon A/S, Vedbaek, Denmark). MicroRNAs were labeled using the miRCURY ${ }^{\mathrm{TM}}$ Hy3 $3^{\mathrm{TM}} / \mathrm{Hy}^{\mathrm{TM}}$ Power kit and hybridized onto the miRCURY ${ }^{\mathrm{TM}}$ LNA (v.18.0) (Exiqon A/S). After washing with the washing buffer in the kit, the slides were scanned using the Axon GenePix 4000B Microarray Scanner, and the data were analyzed using GenePix Pro 6.0 software (Molecular Devices, LLC, Sunnyvale, CA, USA) $(21,22)$.

Analysis of clinical samples and miRNAs. The protocol of this study was approved by the Ethics Committee of the First Affiliated Hospital of Zhejiang University School of Medicine. Written informed consent was obtained from all patients. In this study, 45 bone marrow samples from patients with AML were collected at our hospital from 2013-2014, in strict accordance with the approved protocol. The information of the patients in this experiment is summarized in Table I. Total RNA, including small RNAs, was isolated using the mirVana PARIS miRNA isolation kit from blood mononuclear cells isolated using Ficoll-Paque PLUS (GE Healthcare, Milwaukee, WI, USA), as described previously (23). RT-qPCR for the analysis of microRNAs was performed using the miScript SYBR Green PCR kit (Qiagen GmbH, Hilden, Germany). c-Abl served as 
- VEGFa-O QVEGFa-shRNA 口NC-LV

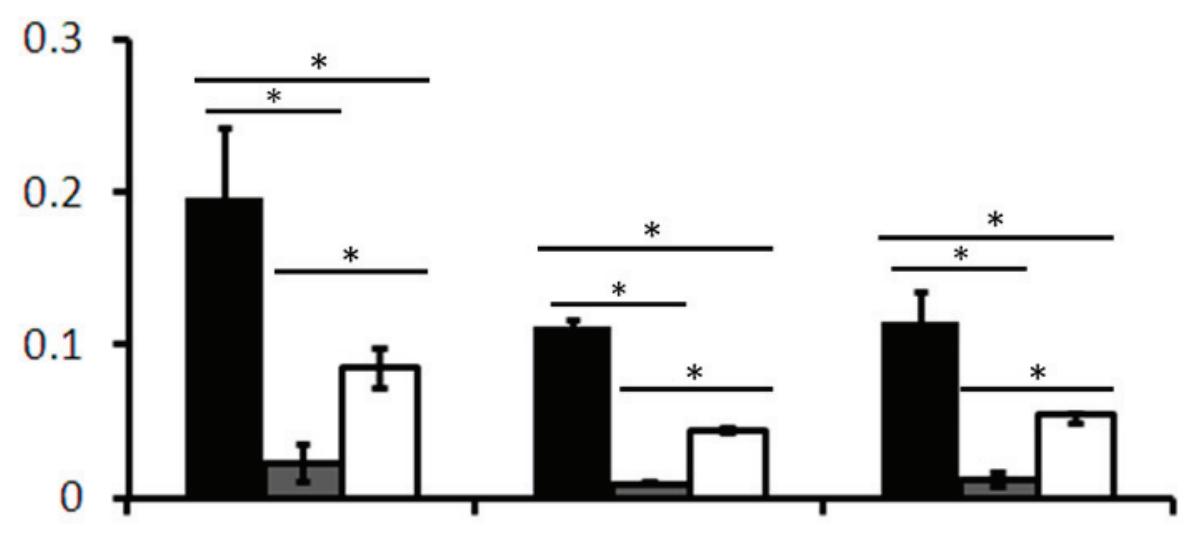

K562 HL-60 U937
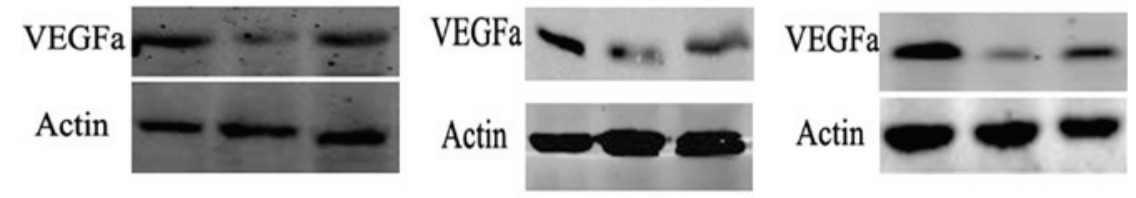

Figure 1. Relative mRNA expression levels of VEGF in leukemia cells. VEGF overexpression and knockdown were achieved in the three cell lines, as confirmed by reverse transcription-polymerase chain reaction and western blotting. The background expression of VEGF was at a high level in leukemia cells and genetic manipulation resulted in significantly altered expression of VEGF in the cells ( $\mathrm{P}<0.01)$. VEGFa-O, overexpression of VEGF gene; VEGFa-shRNA, knockdown of VEGF; NC-LV, controls.

the internal control gene. The relative expression levels of microRNAs were calculated using the $2^{-\Delta \Delta C q}$ method (19). Furthermore, the mRNA expression levels of VEGF in the bone marrow samples were determined by RT-qPCR. The expression levels of VEGF were subsequently ranked from maximum to minimum and then divided into high and low groups.

Statistical analysis. SPSS 19.0 software (SPSS Inc., Chicago, IL, USA) was used for statistical analysis. One-way analysis of variance was performed for the comparisons of three groups and Student's t-test for two groups. $\mathrm{P}<0.05$ was considered to indicate a statistically significant difference.

\section{Results}

Construction of AML cells with stable expression of VEGF and knockdown of VEGF. To confirm that cells with stable knockdown and overexpression of VEGF were obtained, we extracted total protein for western blotting and total RNA for RT-qPCR. The RT-qPCR analysis showed that the mRNA expression levels of VEGF were significantly higher in K562-VEGFa-O, HL-60-VEGFa-O and U937-VEGFa-O cells compared with the control cells (K562-NC-LV, HL-60-NC-LV and U937-NC-LV) $(\mathrm{P}<0.01)$, and that those of K562-VEGF-shRNA, HL-60-VEGF-shRNA and U937-VEGF-shRNA cells were significantly lower compared with the control cells $(\mathrm{P}<0.01$; Fig. 1A). In addition, the results of western blotting confirmed that the VEGF protein had a pattern of expression that resembled that of its mRNA (Fig. 1B).

VEGF changes the microRNA profile of leukemia cells. For the detection of microRNA profiles, total RNA was extracted from the cells for microarray analysis. Genes that were screened using the microarray needed to meet the criteria of $\geq 2$-fold increase or decrease in expression in the cells with overexpression or knockdown of VEGF compared with the controls. Overexpression of VEGF in leukemia cells (K562-VEGFa-O, HL-60-VEGFa-O and U937-VEGFa-O), despite being upregulated by 3 -fold, had little effect on microRNA expression; only four microRNAs were identified as being altered in expression, including has-miR-1273f and has-miR-4679, which were upregulated, and eb-miR-BART10-3p and has-miR-3925-3p, which were downregulated (Fig. 2A),

In K562-VEGF-shRNA, HL-60-VEGF-shRNA and U937-VEGF-shRNA cells, microRNA profiling showed a significant change compared with control cells (K562-NC-LV, HL-60-NC-LV and U937-NC-LV). Among several microRNAs that showed a 5-fold change in expression, hsv2-miR-H12, has-miR-124-5p, has-miR-3924 and has-miR-4514 were upregulated, and 33 microRNAs, including has-miR-20a, were downregulated (Fig. 2B).

Expression of microRNAs associated with VEGF expression in human samples from AML patients. In the present study, several microRNAs showed changes in their levels of expression following overexpression or silencing of the expression of the VEGF gene. To confirm these results, bone marrow samples from 45 patients with AML were used to analyze the expression levels of microRNAs identified in the microarray and VEGF. Subsequently, the expression levels of VEGF were defined into low and high groups. The results indicated a positive association between VEGF expression and the expression of six microRNAs, including miR-20a, miR-93, miR-16-5p, 

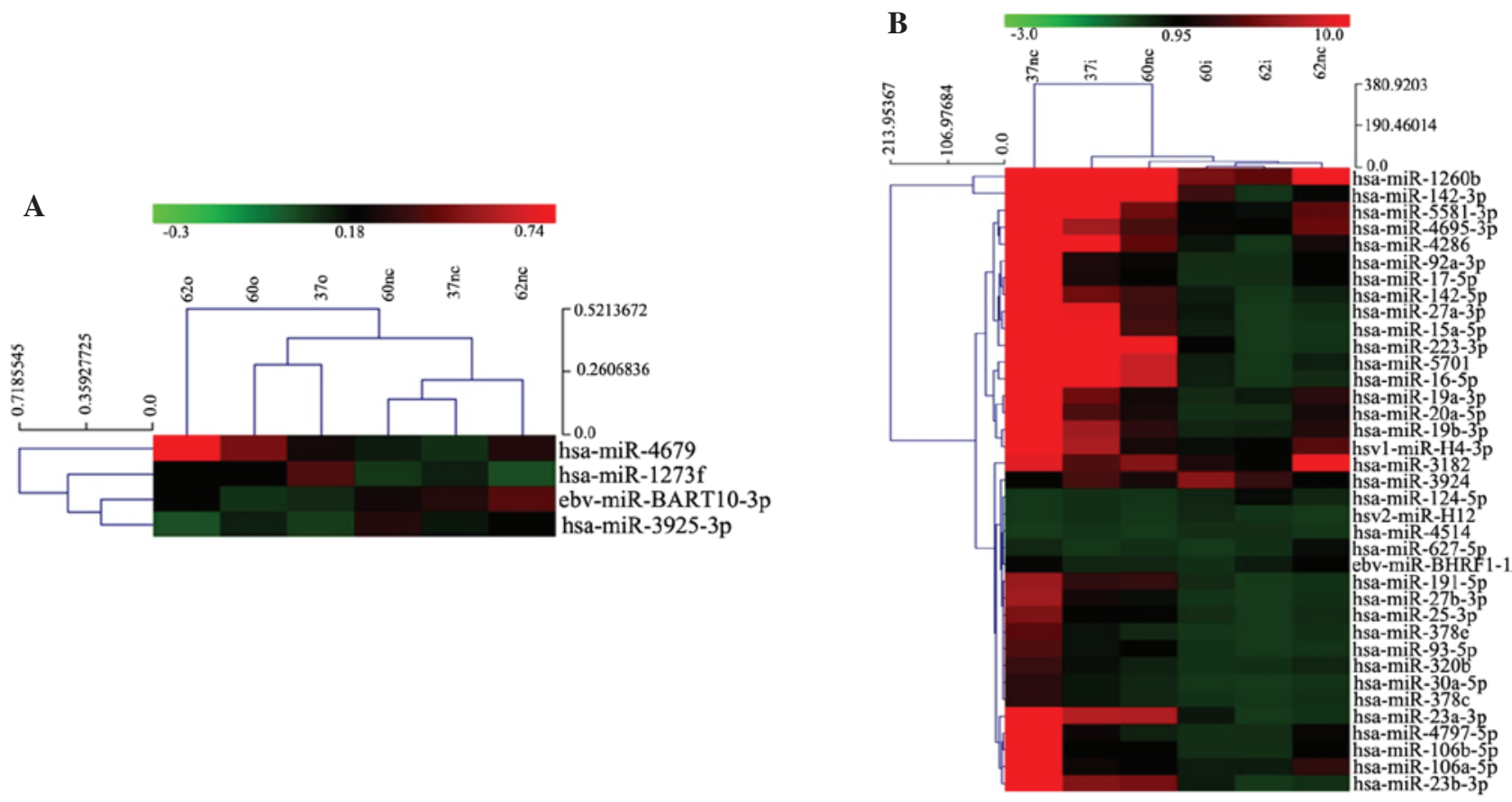

Figure 2. microRNA expression profiles of leukemia cells with different expression levels of VEGF. Changes in the microRNA expression profiles of (A) VEGF-overexpressing leukemia cells and (B) VEGF-knockdown leukemia cells, as compared with the control cells. All microRNAs shown in the figure have $\geq 2$-fold change in expression compared with the control cells. VEGF, vascular endothelial growth factor.
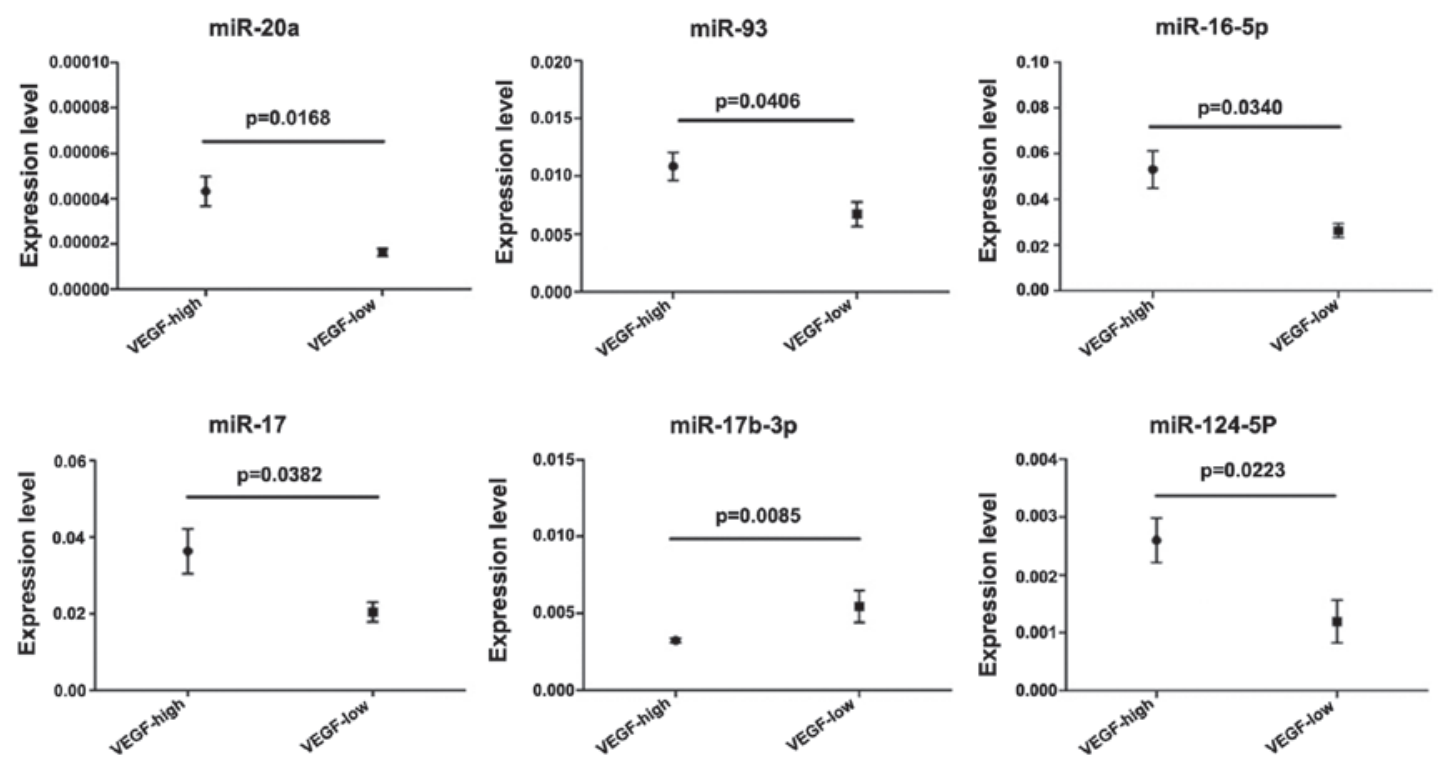

Figure 3. Expression levels of miR-20a, miR-93, miR-16-5p, miR-17, miR-124-5p and miR-17b-3p in AML patients with high or low expression of VEGF The expression levels of VEGF in the bone marrow samples were determined by reverse transcription-quantitative polymerase chain reaction, and were then ranked from maximum to minimum and divided into two high and low groups. microRNA expression levels were analyzed and compared. VEGF, vascular endothelial growth factor.

miR-17-5p, miR-17b-3p and miR-124-5p. In addition, a negative association was observed between VEGF expression and the expression of miR-17b-3p (Fig. 3).

\section{Discussion}

Elevated expression of the VEGF gene is commonly observed in major types of cancer, including AML, and is essential for angiogenesis, which supplies nutrients, oxygen and other factors for the rapid proliferation and growth of malignancies $(2-4,6,8)$. VEGF could play important roles in various physical events of malignant cells using autocrine or paracrine pathways (24-30). VEGF and its receptors are commonly upregulated in bone marrow precursor cells and leukemia progenitor cells and influence the secretion of various factors from bone marrow cells (31). Furthermore, the autocrine pathway of VEGF may have effects on the survival of hematopoietic stem cells, and VEGFR-1 and VEGFR-2 have also 
been shown to contribute to this process (31). Therefore, VEGF performs essential functions in the initiation and development of solid and hematological tumors.

In the present study, a microRNA microarray was used to detect the influence of VEGF on hundreds of microRNAs in leukemia cells. It was observed that overexpression of VEGF had a limited impact on leukemia cells, but that silencing of VEGF significantly altered the microRNA profiles of leukemia cells. At least seven microRNAs (miR-20a, miR-93, miR-16-5p, miR-17, miR-124-5p and miR-17b-3p) were identified in the peripheral blood samples of AML patients, of which six were positively associated, and one (miR-17b-3p) was negatively associated, with VEGF expression.

Among the microRNAs identified, miR-17 and miR-20a belong to the miR-17-92 cluster, which includes six members (miR-17, miR-18a, miR-19a, miR-20a, miR-19b and miR-92a), all of which are spliced from a single pre-RNA (32). This cluster of miRNAs is overexpressed in a variety of cancers, including hematopoietic and solid tumors $(33,34)$. miR-93 is encoded by the polycistronic miR-106b-25 cluster, which contains miR-106, miR-93 and miR-25 (33). The miR-106b-25 cluster is a paralog of the miR-17-92 cluster and both exert similar functions in development and tumorigenesis $(35,36)$. In previous studies, miR-93 could promote angiogenesis, causing endothelial cells to spread and promoting tube formation by suppressing the expression of integrin- $\beta 8$ in brain and breast cancers $(37,38)$. Unlike miR-17, miR-20 and miR-93, miR-124-5p may predominantly have an anticancer effect $(39,40)$. These reports are not completely consistent with the results of the present study, which showed that a lower level of VEGF was associated with downregulation of miR-124-5p. miR-17-3p, whose precursor is microRNA-17, is a passenger strand microRNA that is able to target and repress the expression of TIMP metallopeptidase inhibitor 3, phosphatase and tensin homolog deleted on chromosome 10, GalNT7 and vimentin, all of which are known to promote the proliferation and metastasis of cancer cells $(41,42)$. These reports are in agreement with the results of the present study.

Previous studies have determined that AML and other subtypes of leukemia show elevated expression of VEGF and its receptors $(4,9,43-45)$. The results of the present study suggested that knockdown of VEGF could induce large changes in the expression of microRNAs, likely because VEGF signaling has an important role in the development and progression of AML cells. The differences in the results of the microarray and clinical samples may be due to the differences between the immortal cell lines and AML cells in patients, which emphasizes the requirement for further clinical examinations.

In conclusion, the present study demonstrated that autocrine or paracrine expression of VEGF by AML cells directly or indirectly affected AML cells themselves or neighboring cells. The changes in the microRNA expression profile of leukemia cells following downregulation of VEGF suggests that several targets for anti-AML therapy may exist in the VEGF-microRNA axis. Additional related studies are required in the future to address this.

\section{Acknowledgements}

The authors would like to thank Dr Guowei Qu for his critical suggestions on the processing of data and design of experiments. This study was supported by grants from the Science and Technology Department of Zhejiang Province (no. 2011C23015), Zhejiang Provincial Department of Education (no. Y201120523) and Zhejiang Provincial Administration of Traditional Chinese Medicine (no. Y201120523).

\section{References}

1. Kerbel RS: Tumor angiogenesis. N Engl J Med 358: 2039-2049, 2008.

2. Olsson AK, Dimberg A, Kreuger J and Claesson-Welsh L: VEGF receptor signalling-in control of vascular function. Nat Rev Mol Cell Biol 7: 359-371, 2006.

3. Song G, Li Y and Jiang G: Role of VEGF/VEGFR in the pathogenesis of leukemias and as treatment targets (Review). Oncol Rep 28: 1935-1944, 2012.

4. Estey E and Döhner H: Acute myeloid leukaemia. Lancet 368: 1894-1907, 2006.

5. O'Donnell MR, Abboud CN, Altman J, Appelbaum FR, Arber DA, Attar E, Borate U, Coutre SE, Damon LE, Goorha S, et al: Acute myeloid leukemia. J Natl Compr Canc Netw 10: 984-1021, 2012.

6. Hou HA, Chou WC, Lin LI, Tang JL, Tseng MH, Huang CF, Yao M, Chen CY, Tsay W and Tien HF: Expression of angiopoietins and vascular endothelial growth factors and their clinical significance in acute myeloid leukemia. Leuk Res 32: 904-912, 2008.

7. Kampen KR, Ter Elst A and de Bont ES: Vascular endothelial growth factor signaling in acute myeloid leukemia. Cell Mol Life Sci 70: 1307-1317, 2013.

8. Padró T, Bieker R, Ruiz S, Steins M, Retzlaff S, Bürger H, Büchner T, Kessler T, Herrera F, Kienast J, et al: Overexpression of vascular endothelial growth factor (VEGF) and its cellular receptor KDR (VEGFR-2) in the bone marrow of patients with acute myeloid leukemia. Leukemia 16: 1302-1310, 2002.

9. Hiramatsu A, Miwa H, Shikami M,Ikai T, Tajima E, Yamamoto H, Imai N, Hattori A, Kyo T, Watarai M, et al: Disease-specific expression of VEGF and its receptors in AML cells: Possible autocrine pathway of VEGF/type1 receptor of VEGF in $t(15 ; 17)$ AML and VEGF/type 2 receptor of VEGF in $t(8 ; 21)$ AML. Leuk Lymphoma 47: 89-95, 2006.

10. Santos SC and Dias S: Internal and external autocrine VEGF/KDR loops regulate survival of subsets of acute leukemia through distinct signaling pathways. Blood 103: 3883-3889, 2004.

11. Bartel DP: MicroRNAs: Genomics, biogenesis, mechanism, and function. Cell 116: 281-297, 2004.

12. Garzon R, Garofalo M, Martelli MP, Briesewitz R, Wang L, Fernandez-Cymering C, Volinia S, Liu CG, Schnittger S, Haferlach T, et al: Distinctive microRNA signature of acute myeloid leukemia bearing cytoplasmic mutated nucleophosmin. Proc Natl Acad Sci USA 105: 3945-3950, 2008.

13. Garzon R, Volinia S, Liu CG, Fernandez-Cymering C, Palumbo T, Pichiorri F, Fabbri M, Coombes K, Alder H, Nakamura T, et al: MicroRNA signatures associated with cytogenetics and prognosis in acute myeloid leukemia. Blood 111: 3183-3189, 2008 .

14. Ritchie WJ, Flamant S and Rasko J: MicroRNA in acute myeloid leukemia. N Engl J Med 359: 653; author reply 653-654, 2008.

15. Havelange V, Stauffer N, Heaphy CC, Volinia S, Andreeff M, Marcucci G, Croce CM and Garzon R: Functional implications of microRNAs in acute myeloid leukemia by integrating microRNA and messenger RNA expression profiling. Cancer 117: 4696-4706, 2011.

16. Wei J,Zhao ZX, Li Y,Zhou ZQ and You TG: Cortactin expression confers a more malignant phenotype to gastric cancer SGC-7901 cells. World J Gastroenterol 20: 3287-3300, 2014.

17. Hayashita Y, Osada H, Tatematsu Y, Yamada H, Yanagisawa K, Tomida S, Yatabe Y, Kawahara K, Sekido Y and Takahashi T: A polycistronic microRNA cluster, miR-17-92, is overexpressed in human lung cancers and enhances cell proliferation. Cancer Res 65: 9628-9632, 2005.

18. Li S, Moffett HF, Lu J, Werner L, Zhang H, Ritz J, Neuberg D, Wucherpfennig KW, Brown JR and Novina CD: MicroRNA expression profiling identifies activated B cell status in chronic lymphocytic leukemia cells. PloS One 6: e16956, 2011.

19. Livak KJ and Schmittgen TD: Analysis of relative gene expression data using real-time quantitative PCR and the 2(-Delta Delta C(T)) Method. Methods 25: 402-408, 2001. 
20. Wei R, Yuan D, Wang T, Zhou C, Lin F, Chen H, Wu H, Yang S Wang Y, Liu J, et al: Characterization, tissue distribution and regulation of agouti-related protein (AgRP) in a cyprinid fish (Schizothorax prenanti). Gene 527: 193-200, 2013.

21. Ward IM and Chen J: Histone H2AX is phosphorylated in an ATR-dependent manner in response to replicational stress. J Biol Chem 276: 47759-47762, 2001.

22. Gao W, Yu Y, Cao H, Shen H, Li X, Pan S and Shu Y: Deregulated expression of miR-21, miR-143 and miR-181a in non small cell lung cancer is related to clinicopathologic characteristics or patient prognosis. Biomed Pharmacother 64: 399-408, 2010.

23. Lutherborrow M, Bryant A, Jayaswal V, Agapiou D, Palma C, Yang YH and Ma DD: Expression profiling of cytogenetically normal acute myeloid leukemia identifies microRNAs that target genes involved in monocytic differentiation. Am J Hematol 86: $2-11,2011$.

24. Kirschner MB, Kao SC, Edelman JJ, Armstrong NJ, Vallely MP, van Zandwijk N and Reid G: Haemolysis during sample preparation alters microRNA content of plasma. PloS One 6: e24145, 2011

25. Koch KR, Refaian N, Hos D, Schlereth SL, Bosch JJ, Cursiefen C and Heindl LM: Autocrine impact of VEGF-A on uveal melanoma cells. Invest Ophthalmol Vis Sci 55: 2697-2704, 2014.

26. Larsen AK, Poindessous V, Sabbah M, de Gramont A and Mesange P: Autocrine signaling plays a major role in the response of colorectal cancer cells to VEGF blockage. International Journal of Molecular Medicine 34: S22-S22, 2014.

27. Barr MP, Gray G, Gately KA, Harns E, Fallon PG, Davies AM Richard DJ, Pidgeon GP, Cuffe S, Finn S and O'Byrne KJ: VEGF autocrine survival signalling is mediated via neuropilin 1 receptor in NSCLC cells. Lung Cancer 83: S5-S5, 2014.

28. Ji Y, Chen S, Li K, Xiao X, Xu T and Zheng S: Upregulated autocrine vascular endothelial growth factor (VEGF)/VEGF receptor-2 loop prevents apoptosis in haemangioma-derived endothelial cells. Brit J Dermatol 170: 78-86, 2014.

29. Barr MP, Gray SG, Gately KA and O'Byrne K: Vegf is an autocrine survival factor in non-small cell lung cancer, mediating its effects via the neuropilin-1 receptor. J Thorac Oncol 8: S426-S426, 2013.

30. Lee S, Chen TT, Barber CL, Jordan MC, Murdock J, Desai S, Ferrara N, Nagy A, Roos KP and Iruela-Arispe ML: Autocrine VEGF signaling is required for vascular homeostasis. Cell 130: 691-703, 2007.

31. Reinmuth N, Liu W, Jung YD, Ahmad SA, Shaheen RM, Fan F, Bucana CD, McMahon G, Gallick GE and Ellis LM: Induction of VEGF in perivascular cells defines a potential paracrine mechanism for endothelial cell survival. FASEB J 15: 1239-1241, 2001.

32. Bellamy WT, Richter L, Sirjani D, Roxas C, Glinsmann-Gibson B, Frutiger Y, Grogan TM and List AF: Vascular endothelial cel growth factor is an autocrine promoter of abnormal localized immature myeloid precursors and leukemia progenitor formation in myelodysplastic syndromes. Blood 97: 1427-1434, 2001.

33. van Haaften G and Agami R: Tumorigenicity of the miR-17-92 cluster distilled. Genes Dev 24: 1-4, 2010.
34. Volinia S, Calin GA, Liu CG, Ambs S, Cimmino A, Petrocca F, Visone R, Iorio M, Roldo C, Ferracin M, et al: A microRNA expression signature of human solid tumors defines cancer gene targets. Proc Natl Acad Sci USA 103: 2257-2261, 2006.

35. Poliseno L, Salmena L, Riccardi L, Fornari A, Song MS, Hobbs RM, Sportoletti P, Varmeh S, Egia A, Fedele G, et al: Identification of the miR-106b 25 microRNA cluster as a proto-oncogenic PTEN-targeting intron that cooperates with its host gene MCM7 in transformation. Sci Signal 3: ra29, 2010.

36. Xiao C, Srinivasan L, Calado DP, Patterson HC, Zhang B, Wang J, Henderson JM, Kutok JL and Rajewsky K: Lymphoproliferative disease and autoimmunity in mice with increased miR-17-92 expression in lymphocytes. Nat Immunol 9: 405-414, 2008.

37. Ventura A, Young AG, Winslow MM, Lintault L, Meissner A, Erkeland SJ, Newman J, Bronson RT, Crowley D, Stone JR, et al: Targeted deletion reveals essential and overlapping functions of the miR-17- through 92 family of miRNA clusters. Cell 132: 875-886, 2008

38. Fang L, Deng Z, Shatseva T, Yang J, Peng C, Du WW, Yee AJ, Ang LC, He C, Shan SW and Yang BB: MicroRNA miR-93 promotes tumor growth and angiogenesis by targeting integrin- $\beta 8$. Oncogene 30: 806-821, 2011.

39. Fang L, Du WW, Yang W, Rutnam ZJ, Peng C, Li H, O'Malley YQ, Askeland RW, Sugg S, Liu M, et al: MiR-93 enhances angiogenesis and metastasis by targeting LATS2. Cell Cycle 11: 4352-4365, 2012.

40. Jinushi T, Shibayama Y, Kinoshita I, Oizumi S, Jinushi M, Aota T, Takahashi T, Horita S, Dosaka-Akita H and Iseki K: Low expression levels of microRNA-124-5p correlated with poor prognosis in colorectal cancer via targeting of SMC4. Cancer Med 3: 1544-1552, 2014.

41. Chen Q, Lu G, Cai Y, Li Y, Xu R, Ke Y and Zhang S: MiR-124-5p inhibits the growth of high-grade gliomas through posttranscriptional regulation of LAMB1. Neuro Oncol 16: 637-651, 2014

42. Yang X, Du WW, Li H, Liu F, Khorshidi A, Rutnam ZJ and Yang BB: Both mature miR-17-5p and passenger strand miR-17-3p target TIMP3 and induce prostate tumor growth and invasion. Nucleic Acids Res 41: 9688-9704, 2013.

43. Shan SW, Fang L, Shatseva T, Rutnam ZJ, Yang X, Du W, Lu W, Xuan JW, Deng Z and Yang BB: Mature miR-17-5p and passenger miR-17-3p induce hepatocellular carcinoma by targeting PTEN, GalNT7 and vimentin in different signal pathways. J Cell Sci 126: 1517-1530, 2013.

44. Ruan GR, Liu YR, Chen SS, Fu JY, Chang Y, Qin YZ, Li JL, $\mathrm{Yu} \mathrm{H}$ and Wang $\mathrm{H}$ : Effect of antisense VEGF cDNA transfection on the growth of chronic myeloid leukemia K562 cells in vitro and in nude mice. Leuk Res 28: 763-769, 2004

45. Bamba H, Ota S, Kato A, Kawamoto C and Fujiwara K: Prostaglandins up-regulate vascular endothelial growth factor production through distinct pathways in differentiated U937 cells. Biochem Biophys Res Commun 273: 485-491, 2000. 